\title{
Effect of Oxytocin Treatment on Asprosin Serum Level and Liver Function Changes in Rats with Streptozotocin-Induced Diabetes
}

\author{
KHALED A.A. ABULFADLE, M.D. and RANIA R.A. ATIA, M.D. \\ The Department of Physiology, Faculty of Medicine, Zagazig University, Zagazig, Egypt
}

\begin{abstract}
Background: Asprosin is a newly discovered hormone that was found to be increased in cases of type 2 diabetes mellitus but, few data were available on its serum level changes in cases of streptozotocin (STZ) induced diabetes. Also, studies on the effect of STZ induced diabetes on liver functions were limited. In addition, exogenous oxytocin treatment was recorded to improve glucose homeostasis in cases of type 2 diabetes mellitus and insulin resistance, but, the information about its effect on STZ induced diabetes was few.
\end{abstract}

Aim of Study: To investigate the effect of exogenous oxytocin treatment on asprosin serum level and liver function changes in rats with STZ-induced diabetes.

Material and Methods: 24 Rats were divided equally into 4 groups; control group, streptozotocin treated (STZ) group, streptozotocin treated and pretreated with oxytocin (pre-STZ) group, and, streptozotocin treated and post-treated with oxytocin (post-STZ) group. In the control group, $1 \mathrm{ml}$ of saline solution was daily injected intraperitoneally (i.p.) for the $1 \mathrm{st}$ 6 days and the last 5 days of this 39 days study. In STZ group, a single dose of STZ $(60 \mathrm{mg} / \mathrm{kg}$, freshly dissolved in $1 \mathrm{ml}$ of saline solution) was injected i.p. on the 6 th day after initial $1 \mathrm{ml}$ of saline solution was daily injected i.p. for the 1 st 5 days. Also, $1 \mathrm{ml}$ saline/day was injected i.p. in the last 5 days of the study. In Pre-STZ group, $5 \mathrm{gg} / \mathrm{m}$ of oxytocin was daily injected i.p. for 5 days prior to the administration of a single dose of STZ injection and in the last 5 days of the study, $1 \mathrm{ml}$ of saline was injected i.p. daily. In post-STZ group, $5 \mathrm{gg}$ of oxytocin was daily injected i.p. for 5 days beginning by 28 th day following the administration of single dose of STZ injection on the 5 th day which was preceded by 5 days i.p. therapy with $1 \mathrm{ml}$ of saline/day. At the end of the study, rats were fasted overnight and were killed by decapitation while anaesthetized with ether. Blood from each rat was collected and divided into two parts, a part was kept in heparinized tubes for estimation of glycosylated hemoglobin ( $\mathrm{HbA} 1 \mathrm{c}$ ) and the other part was left in non-heparinized tubes to clot and was centrifuged to separate serum which was stored at $25^{\circ} \mathrm{C}$ till used for chemical assays.

Results: In STZ group, there was a significant $(p<0.001)$ increase in serum levels of glucose, total cholesterol (TC),

Correspondence to: Dr. Khaled A.A. Abulfadle, E-Mail: khafadle@gmail.com triglycerides (TG), low density lipoprotein (LDL), very low density lipoprotein (VLDL), tumor necrosis factor alpha $(\mathrm{TNF} \alpha), \% \mathrm{HbA} 1 \mathrm{c}$ and atherogenic index, but, there was a significant $(p<0.001)$ decrease in final body mass index (BMI) and serum levels of each of insulin, C-peptide and high density lipoprotein (HDL), in comparison to the control group. Also, serum asprosin level was significantly $(p<0.001)$ reduced in STZ group in comparison to the control. Moreover, significant $(p<0.001)$ increases in serum levels of aspartate aminotransferase (AST), alanine aminotransferase (ALT), alkaline phosphatase (ALP) and total bilirubin, but, significant $(p<0.001)$ decreases in serum direct bilirubin, total protein and albumin levels were found. Furthermore, there were positive associations between serum asprosin and each of final BMI ( $r=0.948$, $p<0.01)$, serum insulin $(r=0.946, p<0.01)$, serum C-peptide $(r=0.85, p<0.05)$, serum HDL $(r=0.936, p<0.01)$, serum direct bilirubin $(r=0.902, p<0.05)$, serum total protein $(r=0.867$, $p<0.05)$ and serum albumin $(r=0.942, p<0.01)$, but, negative correlations between serum asprosin and each of serum glucose $(r=0.979, p<0.001)$, serum TC $(r=0.966, p<0.01)$, serum TG $(r=0.969, p<0.01)$, serum LDL $(r=0.942, p<0.01)$, serum VLDL $(r=0.858, p<0.05), \% \mathrm{HbA} 1 \mathrm{c}(r=0.918, p<0.01)$, serum TNF $\pm(r=-0.96, p<0.01)$, atherogenic index $(r=0.97$, $p<0.01)$, serum AST $(r=0.977, p<0.001)$, serum ALT $(r=0.952, p<0.01)$, serum ALP $(r=-0.958, p<0.01)$ and serum total bilirubin $(r=0.925, p<0.01)$. On the other hand, in preSTZ group a significant $(p<0.001)$ decrease in serum levels of glucose, TC, TG, LDL, VLDL, TNF $\alpha, \% \mathrm{HbA} 1 \mathrm{c}$ and

$\begin{array}{ll}\text { Abbreviations } & \\ \text { STZ } & \text { : Streptozotocin. } \\ \text { STZ group } & \text { : Streptozotocin treated group. } \\ \text { Pre-STZ group } & : \begin{array}{l}\text { Streptozotocin treated and pretreated with } \\ \text { oxytocin group }\end{array} \\ \text { Post-STZ group } & \text { : Streptozotocin treated and post-treated with } \\ & \text { oxytocin group. } \\ \text { BMI } & : \text { Body mass index. } \\ \text { TC } & : \text { Total cholesterol. } \\ \text { TG } & : \text { Triglycerides. } \\ \text { HDL } & \text { : High-density lipoprotein. } \\ \text { VLDL } & : \text { Glycosylated hemoglobin. } \\ \text { HbA1c } & : \text { Tumor necrosis factor alpha. } \\ \text { TNF } \alpha & : \text { Aspartate aminotransferase. } \\ \text { AST } & : \text { Alanine aminotransferase. } \\ \text { ALT } & : \text { Alkaline phosphatase. } \\ \text { ALP } & \end{array}$


atherogenic index, but, there was a significant increase in final BMI $(p<0.01)$ and serum levels $(p<0.001)$ of each of insulin, asprosin, C-peptide and HDL, in comparison to the STZ group was found. Also, significant $(p<0.001)$ decreases in serum levels of AST, ALT, ALP and total bilirubin, but, significant $(p<0.001)$ increases in serum direct bilirubin, total protein and albumin levels in comparison to the STZ group were found. In post-STZ group, there was a significant $(p<0.001)$ decrease in serum levels of glucose, TC, TG, LDL, VLDL, TNF $\alpha, \%$ HbA1c and atherogenic index, but, a significant increase $(p<0.001)$ in serum levels of insulin, asprosin, C-peptide and HDL, in comparison to the STZ group. Also, significant $(p<0.001)$ decreases in serum levels of AST, ALT, ALP and total bilirubin, but, significant $(p<0.001)$ increases in serum direct bilirubin, total protein and albumin levels were found in comparison to the STZ group.

Conclusion: Asprosin levels were significantly decreased in cases of STZ induced diabetes in comparison with the control, but, increased with oxytocin treatment whether before or after STZ treatment in comparison with STZ group. Also, in STZ group, asprosin was positively correlated with final BMI, serum insulin, serum HDL, serum direct bilirubin, total protein and albumin, but, negatively associated with serum glucose, TC, TG, LDL, VLDL, TNF x, AST, ALT, ALP, total bilirubin, HbA1c and atherogenic index. Thus, changes in circulating asprosin affected glucose homeostasis and subsequently the pathogenesis and complications of diabetes mellitus and might be a predictor of early diagnosis in diabetes mellitus. Also, in STZ group, liver functions were affected in the form of a significant increase in liver enzymes and total bilirubin but, a significant decrease in direct bilirubin, total protein and albumin. Oxytocin treatment pre or post STZ treatment protected or restored the functional $\beta$-cells, and, improved lipid profile and liver functions.

Key Words: Asprosin-Oxytocin-Streptozotocin-Diabetes Mellitus - Liver Function.

\section{Introduction}

ASPROSIN, a protein hormone, was discovered by Romere, Duerrschmid [1] and shared in regulation of glucose homeostasis. It is the C-terminal cleavage product of profibrillin and is regulated with the starvation and causes hepatic glucose release by activating hepatic G protein-cAMPPKA way [2]. Kader, Meltem [3] found that asprosin deficiency in human caused lipodystrophy with reduced plasma insulin. Wang, Qu [4] stated that adipose tissue is considered as an endocrine organ secreting adipokines as asprosin, which participated in the pathologic processes of diabetes mellitus. Asprosin was named after the Greek word for white (aspros), because of the decrease in subcutaneous white adipose tissue that was found in asprosin-deficient patients and because white adipose tissue is a source of plasma asprosin [2] It was found that plasma asprosin displayed circadian oscillation with an acute drop in levels coinciding with the onset of feeding, while, overnight fasting and insulin resistance increased its circulating levels [1,2]. Also, Wang, Qu [4] found that plasma asprosin levels were significantly higher in patients with type 2 diabetes mellitus in comparison to control persons. Streptozotocin (STZ) was commonly used for induction of experimental diabetes and it affected pancreatic $\beta$-cells causing changes in insulin and glucose blood levels [5] STZ was taken up by pancreatic $\beta$-cells with glucose transporter GLUT2 and blocked glucoseinduced insulin secretion and it also enhanced oxidative stress of $\beta$-cells [6] . Oxytocin is a hypothalamic nonapeptide synthesized in the magnocellular neurons of the paraventricular and supraoptic nuclei projecting to the pituitary, where it reaches the peripheral circulation, as well as in the parvocellular neurons of the paraventricular nucleus projecting to other brain regions [7]. Classically, oxytocin has been involved in uterine contractions during labor and milk ejection during lactation, and its major applications in clinics is for labor induction $[8]$ and postpartum hemorrhage [8]. Further studies showed that oxytocin was involved in several other functions, such as natriuresis, insulin and glucagon secretion, food intake and body weight [9]. Type I diabetes mellitus most commonly refers to individuals suffering from diabetes mellitus due to pancreatic $\beta$-islet cell death who have a greater tendency to develop ketoacidosis due to a lack of insulin secretion [6] As a result, patients who suffer from type I diabetes mellitus are often prescribed exogenous insulin as a preventative measure against the progression to diabetic ketoacidosis [10]. Oxytocin stimulated insulin release and had insulin-like characteristics [11]. Also, Yip [12] demonstrated a decrease in blood glucose levels in diabetic mice upon chronic administration of oxytocin. Moreover, oxytocin promoted glucose uptake in muscle cells [11], and the presence of oxytocin receptors in rodent islets of Langerhans confirmed its involvement in the release of insulin and glucagon [13]. Furthermore, oxytocin neurons in the supraoptic nucleus of the hypothalamus have been found to serve as glucose sensors [14] . Alanine transaminase (ALT) is a widely available serum marker of liver disease. Even a minor elevation of ALT is a good predictor of mortality from liver disease [15]. West, Brousil [16] and Leeds, Forman [17] found elevated ALT in cases of type I diabetes mellitus in comparison to healthy persons. On the other hand, Olsson, Wesslau [18] and Munns, McCrossin [19] declared that raised liver enzymes in patients with type I diabetes have been limited to small case series. As the asprosin is a newly discovered hormone and few data were available on its serum level changes in cases of STZ induced diabetes. Also, studies on effect of STZ induced diabetes on liver 
functions were limited. Furthermore, studies on the effect of oxytocin treatment on STZ induced diabetes were few. Thus, this study was designed to investigate effect of exogenous oxytocin treatment on asprosin serum level and liver function changes in rats with streptozotocin-induced diabetes.

\section{Patients and Methods}

This work was conducted in Physiology Department in Zagazig College of Medicine from March 2018 to June 2018. 24 adult male albino rats of local strains weighing 190-230gm, obtained from Zagazig Faculty of Veterinary Medicine, housed individually in a light- and temperaturecontrolled room on a $12 \mathrm{~h} / 12 \mathrm{~h}$ light-dark cycle and fed a standard pellet lab chow. Male rats were chosen to eliminate the additional complication of estrous cyclicity, since ovarian hormones may have effects on oxytocin action in peripheral target tissues.

\section{Experimental design:}

Rats were divided equally into 4 groups; control group, streptozotocin treated (STZ) group, streptozotocin treated and pretreated with oxytocin (preSTZ) group, and, streptozotocin treated and posttreated with oxytocin (post-STZ) group. In the control group, $1 \mathrm{ml}$ of saline solution was daily injected intraperitoneally (i.p.) for the ${ }^{1 \mathrm{st}} 6$ days and the last 5 days of this 39 days study. In STZ group, a single dose of STZ $(60 \mathrm{mg} / \mathrm{kg}$, freshly dissolved in $1 \mathrm{ml}$ of saline solution) [20] was injected i.p. on the 6th day after initial $1 \mathrm{ml}$ of saline solution was daily injected i.p. for the ${ }^{1 \text { st }} 5$ days. Also, $1 \mathrm{ml}$ saline/day was injected i.p. in the last 5 days of the study. STZ was obtained from Sigma-Aldrich, USA (CAS. No. 18883-66-4). Rats were fasted for $12 \mathrm{~h}$ before induction of diabetes. Rees and Alcolado [21] declared that administration of STZ in adult rats caused pancreatic swelling and $\beta$-islet cells degeneration and induced experimental diabetes mellitus within 2-4 days. The STZ-treated animals were given 5\% glucose water for $24 \mathrm{~h}$ to prevent mortality due to the initial drug-induced hypoglycemia [22]. In Pre-STZ group, $5 \mu \mathrm{g} / \mathrm{kg}$ of oxytocin was daily injected i.p. for 5 days [6] prior to the administration of a single dose of STZ injection and in the last 5 days of the study, $1 \mathrm{ml}$ of saline was injected i.p. daily. Oxytocin was obtained as syntocinon $10 \mathrm{IU} / \mathrm{ml}(16.7 \mathrm{~g} / \mathrm{n})$ from Novartis, Egypt. In post-STZ group, $5 \mathrm{gg} / \mathrm{kg}$ of oxytocin was daily injected i.p. for 5 days beginning by 28 th day following the administration of single dose of
STZ injection on the $5^{\text {th }}$ day [6] which was preceded by 5 days i.p. therapy with $1 \mathrm{ml}$ of saline/day. In STZ group, two days following STZ injection, blood glucose readings using a glucometer were taken and rats with blood glucose levels of $200 \mathrm{mg} /$ dl or higher were considered to be diabetic [5] Animals were weighed before and after experiment. At the end of the study, rats were fasted overnight and were killed by decapitation while anaesthetized with ether. Blood from each rat (about $3.5 \mathrm{ml}$ ) was collected and divided into two parts, a part (about $1 \mathrm{ml}$ ) was kept in heparinized tubes for estimation of glycosylated hemoglobin $(\mathrm{HbA} 1 \mathrm{c})$ and the other part (about $2.5 \mathrm{ml}$ ) was left in non-heparinized tubes for $30 \mathrm{~min}$ to clot at $25 \mathrm{oC}$ and then, it was centrifuged at $3000 \mathrm{rpm}$ for $15 \mathrm{~min}$ to separate serum which was stored at $-25^{\circ} \mathrm{C}$ [23]. Serum was used to investigate levels of asprosin, fasting glucose, insulin, triglycerides (TG), total cholesterol (TC), high-density lipoproteins (HDL), very low-density lipoproteins (VLDL), C-peptide, tumor necrosis factor alpha (TNFct), aspartate aminotransferase (AST), alanine aminotransferase (ALT), alkaline phosphatase (ALP), direct bilirubin, total bilirubin, total protein, albumin. Final body mass index (BMI) in $\mathrm{gm} / \mathrm{cm}^{2}$ was calculated in the different groups, it was estimated just before rats were killed (under ether anesthesia), by dividing body weight $(\mathrm{gm})$ on Length ${ }^{2}\left(\mathrm{~cm}^{2}\right)$ where rat length was identified by measuring the distance between the anus and the nose [24]. Serum levels glucose, insulin, TC, TG and HDL were measured using commercial kits from Sigma-Aldrich, USA (Cat. No. GAGO20, RAB0904, MAK043, TR0100 and MAK045, respectively), while, serum VLDL and asprosin levels were measured using commercial kits (MyBioSource.com) Cat. No. (MBS026726) and (MBS9 395592), respectively. Also, serum levels of CPeptide were estimated using commercial rat ELISA kits (ALPCO, Catalog No. 80-CPTRT-E01). On the other hand, serum TNFa, ALT and AST were investigated using commercial kits (SigmaAldrich Chemicals, USA), Catalog No. (RAB0479), (MAK052) and (MAK055), respectively, while, $\mathrm{HbA} 1 \mathrm{c}$ and serum ALP was measured using commercial kits (MyBiosSource.com), Catalog No. (MBS2033689) and (MBS011598), respectively. Also, serum direct bilirubin and total bilirubin were estimated using commercial kits (MyBiosSource.com), Catalog No. (MBS9389077) and (MBS9389057), respectively, while, serum albumin and total protein were measured using commercial kits (abcam.com, Catalog No. ab108790) and (Biocompare.com, Catalog No. ABIN996403), respectively. 
Low density lipoprotein ( $L D L)$ serum level was calculated using Friedewald formula:

$$
\mathrm{LDL}(\mathrm{mg} / \mathrm{dl})=(\mathrm{TC})-\left[(\mathrm{HDL})+\left(\frac{\mathrm{TG}}{5}\right)\right][25] .
$$

Atherogenic index was calculated using the following formula:

$$
\text { Atherogenic index }=\frac{\mathrm{TC}-\mathrm{HDL}}{\mathrm{HDL}}[\mathbf{2 6}] \text {. }
$$

\section{Statistical analysis:}

The obtained data was expressed as mean \pm standard error of the mean (SEM). For statistical significance, one-way ANOVA and Tukey HSD for Post hoc multiple comparisons were used to compare means. The software, IBM SPSS Statistics Version 24 Software for Windows, was used for that purpose. Also, Graph Pad Prism (Version 7 Software for Windows) was used to analyze the Pearson's correlation coefficient between serum levels of asprosin and different studied parameters within STZ group. Significance was considered with $p$-value $\leq 0.05$.

Table (1): Experimental design.

\begin{tabular}{lcccc}
\hline & $\begin{array}{c}\text { Control } \\
\text { group }\end{array}$ & $\begin{array}{c}\text { STZ } \\
\text { group }\end{array}$ & $\begin{array}{c}\text { Pre-STZ } \\
\text { group }\end{array}$ & $\begin{array}{c}\text { Post-STZ } \\
\text { group }\end{array}$ \\
\hline $\begin{array}{l}\text { Duration of study } \\
\text { 1st } 5 \text { days saline i.p. }\end{array}$ & $\begin{array}{c}39 \text { days } \\
\text { 1st } 5 \text { days oxytocin i.p. }\end{array}$ & $\begin{array}{c}39 \text { days } \\
\sqrt{ }\end{array}$ & 39 days & $\begin{array}{c}39 \text { days } \\
\sqrt{ }\end{array}$ \\
STZ i.p. on the 6th day & & $\sqrt{ }$ & $\sqrt{ }$ & $\sqrt{ }$ \\
Saline i.p. on the 6th day & $\sqrt{ }$ & & & $\sqrt{ }$ \\
Last 5 days oxytocin i.p. & & & & \\
Last 5 days saline i.p. & $\sqrt{ }$ & $\sqrt{ }$ & \\
\hline
\end{tabular}

i.p.: Intraperitoneal injection. STZ: Streptozotocin.

\section{Results}

In this study, a single dose of STZ was used to induce diabetes in rats of the STZ group which was confirmed by the clinical findings in this group. The results of this study in that group (Table $2)$ showed a significant $(p<0.001)$ increase in serum levels of glucose, TC, TG, LDL, VLDL, TNF $\alpha$, $\% \mathrm{HbA} 1 \mathrm{c}$ and atherogenic index, but, there was a significant $(p<0.001)$ decrease in final BMI and serum levels of each of insulin, C-peptide and HDL, in comparison to the control group. Also, serum asprosin level was significantly $(p<0.001)$ reduced in STZ group in comparison to the control (Fig. 1). Moreover, on assessing liver function changes in STZ group (Table 3) in comparison with the control group, significant $(p<0.001)$ increases in serum levels of AST, ALT, ALP and total bilirubin, but, significant $(p<0.001)$ decreases in serum direct bilirubin, total protein and albumin levels were found. Furthermore, correlations in STZ group between serum asprosin and different studied parameters (Table 4) declared positive associations with final BMI $(r=0.948, p<0.01)$, serum insulin $(r=0.946, p<0.01)$, serum C-peptide $(r=0.85, p<0.05)$, serum HDL $(r=0.936, p<0.01)$, serum direct bilirubin $(r=0.902, p<0.05)$, serum total protein $(r=0.867, p<0.05)$ and serum albumin $(r=0.942, p<0.01)$, but, negative associations with serum glucose $(r=0.979, p<0.001)$, serum TC $(r=0.966, p<0.01)$, serum TG $(r=-0.969, p<0.01)$, serum LDL $(r=-0.942, p<0.01)$, serum VLDL $(r=-0.858, p<0.05), \% \mathrm{HbA1c}(r=0.918, p<0.01)$, serum TNF $\alpha(r=0.96, p<0.01)$, atherogenic index $(r=0.97, p<0.01)$, serum AST $(r=0.977, p<0.001)$, serum ALT $(r=-0.952, p<0.01)$, serum ALP $(r=0.958, p<0.01)$ and serum total bilirubin $(r=-0.925, p<0.01)$. To study the effect of oxytocin treatment on STZ induced diabetes mellitus, serum level of asprosin and liver function, it was administered to rats in pre-STZ group prior to STZ treatment to study its possible protective effects. The results of this study in pre-STZ group (Table $2)$ showed a significant $(p<0.001)$ decrease in serum levels of glucose, TC, TG, LDL, VLDL, $\mathrm{TNF} \alpha, \% \mathrm{HbA} 1 \mathrm{c}$ and atherogenic index, but, there was a significant increase in final BMI $(p<0.01)$ and serum levels of each of insulin $(p<0.001)$, Cpeptide $(p<0.001)$ and HDL $(p<0.001)$, in comparison to the STZ group. Also, serum asprosin level was significantly $(p<0.001)$ increased in pre-STZ group in comparison to the STZ group (Fig. 1). Moreover, on assessing liver function changes in pre-STZ group (Table 3 ) in comparison with the STZ group, significant $(p<0.001)$ decreases in serum levels of AST, ALT, ALP and total bilirubin, but, significant $(p<0.001)$ increases in serum direct bilirubin, total protein and albumin levels were found. On the other hand, to assess the possible therapeutic effects of oxytocin on STZ induced diabetes mellitus, it was given to rats in the postSTZ group late after STZ treatment. The results of this study in post-STZ group (Table 2) showed a significant $(p<0.001)$ decrease in serum levels of glucose, TC, TG, LDL, VLDL, TNF $\alpha, \% \mathrm{HbA} 1 \mathrm{c}$ and atherogenic index, but, there was a significant increase $(p<0.001)$ in serum levels of insulin, Cpeptide and HDL, in comparison to the STZ group. Also, serum asprosin level was significantly $(p<0.001)$ increased in post-STZ group in comparison to the STZ group (Fig. 1). Moreover, on assessing liver function changes in post-STZ group (Table 3) in comparison with the STZ group, significant $(p<0.001)$ decreases in serum levels of AST, ALT, ALP and total bilirubin, but, significant $(p<0.001)$ increases in serum direct bilirubin, total 
protein and albumin levels were found. In comparison with pre-STZ group, Table (2) showed a significant $(p<0.001)$ increase in serum levels of glucose, TC, TG, LDL, VLDL, TNF $\alpha, \%$ HbA1c and atherogenic index, but, there was a significant decrease $(p<0.001)$ in serum levels of insulin and HDL, in post-STZ group. Also, serum asprosin level was significantly $(p<0.001)$ decreased in postSTZ group in comparison to the pre-STZ group (Fig. 1). Moreover, on assessing liver function changes in post-STZ group (Table 3 ) in comparison with the pre-STZ group, significant $(p<0.001)$ increases in serum levels of AST, ALT, ALP and total bilirubin, but, significant $(p<0.001)$ decreases in serum direct bilirubin, total protein and albumin levels were found.



Fig. (1): Serum asprosin level (ng/ml) changes among different groups. Data was expressed as Mean \pm SEM. $\mathrm{a}_{p}<0.001$ in comparison with the control group $\mathbf{b} p<0.001$ in comparison to the STZ group. $\boldsymbol{c}<<0.001$ in comparison to the Pre-STZ group.

Table (2): Biochemical changes among different groups.

\begin{tabular}{|c|c|c|c|c|}
\hline & Control group & STZ group & Pre-STZ group & Post-STZ group \\
\hline Final BMI $\left(\mathrm{gm} / \mathrm{cm}^{2}\right)$ & $0.7 \pm 0.02$ & $0.57 \pm 0.01 \mathbf{a}$ & $0.64 \pm 0.01 \mathbf{b} \& \mathbf{c}$ & $0.6 \pm 0.01$ a\&d \\
\hline Serum glucose (mg/dl) & $85 \pm 1.73$ & $480.5 \pm 3.63^{\mathbf{a}}$ & $143.17 \pm 3.1$ a\&e & $187.33 \pm 4.11 \mathbf{a , e \& f}$ \\
\hline Serum insulin $(\mu \mathrm{IU} / \mathrm{ml})$ & $25.39 \pm 0.88$ & $6.98 \pm 0.52^{\mathbf{a}}$ & $17.48 \pm 0.31$ a\&e & $13.45 \pm 0.38^{\mathbf{a}^{\prime} \mathbf{e} \& \mathbf{f}}$ \\
\hline Serum C-peptide (ng/L) & $119.74 \pm 0.77$ & $69.08 \pm 0.58^{\mathbf{a}}$ & $101.38 \pm 0.63$ a\&e & $90.48 \pm 0.68^{\mathbf{a}^{\prime} \mathbf{e} \& \mathbf{f}}$ \\
\hline Serum TC (mg/dl) & $87.99 \pm 0.93$ & $168.16 \pm 1.98^{\mathbf{a}}$ & $112.71 \pm 2.23$ a\&e & $136.51 \pm 1.82^{\mathbf{a}^{\prime} \mathbf{e} \& \mathbf{f}}$ \\
\hline Serum TG (mg/dl) & $64.41 \pm 1.03$ & $177.94 \pm 1.5^{\mathbf{a}}$ & $126.01 \pm 1.67^{\mathbf{a} \& \mathbf{e}}$ & $150.89 \pm 1.52^{\mathbf{a}^{\prime} \mathbf{e} \& \mathbf{f}}$ \\
\hline Serum HDL (mg/dl) & $45.44 \pm 0.3$ & $26.77 \pm 0.35^{\mathbf{a}}$ & $38.97 \pm 0.35$ a\&e & $34.92 \pm 0.37 \mathbf{a}^{\mathbf{\prime}} \mathbf{e} \& \mathbf{f}$ \\
\hline Serum LDL (mg/dl) & $29.66 \pm 1.21$ & $105.79 \pm 1.84^{\mathbf{a}}$ & $48.54 \pm 2.43$ a\&e & $71.42 \pm 2.04^{\mathbf{a}^{\prime} \mathbf{e} \& \mathbf{f}}$ \\
\hline Serum VLDL (mg/dl) & $13.19 \pm 0.2$ & $35.81 \pm 0.25^{\mathbf{a}}$ & $23.62 \pm 0.3 \mathbf{a \& e}$ & $29.93 \pm 0.46^{\mathbf{a}^{\prime} \mathbf{e} \& \mathbf{f}}$ \\
\hline Atherogenic index & $0.94 \pm 0.03$ & $5.3 \pm 0.15^{\mathrm{a}}$ & $1.9 \pm 0.07$ a\&e & $2.91 \pm 0.08^{\mathbf{a}} \mathbf{e} \boldsymbol{\& f}$ \\
\hline HbA1c (\%) & $4.24 \pm 0.02$ & $7.39 \pm 0.02^{\mathbf{a}}$ & $6.35 \pm 0.01$ a\&e & $6.89 \pm 0.02^{\mathbf{a} ' \mathbf{e} \& \mathbf{f}}$ \\
\hline Serum TNF $\alpha(\mathrm{pg} / \mathrm{ml})$ & $48.49 \pm 0.79$ & $206.04 \pm 3.01 \mathbf{a}$ & $71.48 \pm 1.22$ a\&e & $111.97 \pm 3.73^{\mathbf{a}} \mathbf{e} \& \mathbf{f}$ \\
\hline \multicolumn{2}{|c|}{$\begin{array}{l}\text { Data was expressed as Mean } \pm \text { SEM. } \\
\text { a } p<0.001 \text { in comparison with the control group. } \\
\text { b } p<0.05 \text { in comparison with the control group. } \\
\text { c } p<0.01 \text { in comparison to the STZ group. } \\
\text { d } p<0.01 \text { in comparison to the Pre-STZ group. } \\
\text { e } p<0.001 \text { in comparison to the STZ group. } \\
f_{p<0.001 \text { in comparison to the Pre-STZ group. }}\end{array}$} & $\begin{array}{l}\text { BMI } \\
\text { TC } \\
\text { TG } \\
\text { HDL } \\
\text { VLDL } \\
\text { HbA1c } \\
\text { TNF } \alpha\end{array}$ & \multicolumn{2}{|c|}{$\begin{array}{l}\text { : Body mass index. } \\
\text { : Total cholesterol. } \\
\text { : Triglycerides. } \\
\text { : High-density lipoprotein. } \\
\text { : Very low-density lipoprotein. } \\
\text { : Glycosylated hemoglobin. } \\
\text { : Tumor necrosis factor alpha. }\end{array}$} \\
\hline
\end{tabular}

Table (3): Liver function changes among different groups.

\begin{tabular}{|c|c|c|c|c|}
\hline & Control group & STZ group & Pre-STZ group & Post-STZ group \\
\hline Serum AST (U/L) & $49.12 \pm 0.54$ & $92.89 \pm 0.74 \mathbf{a}$ & $62.82 \pm 0.77 \mathbf{a \& b}$ & $76.3 \pm 0.75^{\mathbf{a}} \mathbf{b} \& \mathbf{c}$ \\
\hline Serum ALT (U/L) & $25.55 \pm 0.49$ & $60.3 \pm 0.54^{a}$ & $37 \pm 0.33 \mathbf{a \& b}$ & $48.69 \pm 0.28^{\mathbf{a}^{\prime} \mathbf{b} \& \mathbf{c}}$ \\
\hline Serum ALP (U/L) & $131 \pm 0.41$ & $211.05 \pm 0.61^{\mathbf{a}}$ & $150.72 \pm 0.66^{\mathbf{a} \& \mathbf{b}}$ & $182.65 \pm 0.75^{\mathbf{a}^{\prime} \mathbf{b} \& \mathbf{c}}$ \\
\hline Serum total bilirubin $(\mathrm{mg} / \mathrm{dl})$ & $0.71 \pm 0.01$ & $1.47 \pm 0.01 \mathrm{a}$ & $0.91 \pm 0.01 \mathbf{a \& b}$ & $1.22 \pm 0.01 \mathbf{a}, \mathbf{b} \& \mathbf{c}$ \\
\hline Serum direct bilirubin $(\mathrm{mg} / \mathrm{dl})$ & $0.37 \pm 0.005$ & $0.18 \pm 0.006^{\mathbf{a}}$ & $0.3 \pm 0.007^{\mathbf{a} \& \mathbf{b}}$ & $0.26 \pm 0.004^{\mathbf{a}^{\prime} \mathbf{b} \& \mathbf{c}}$ \\
\hline Serum total protein $(\mathrm{gm} / \mathrm{dl})$ & $5.3 \pm 0.01$ & $3.62 \pm 0.02^{\mathrm{a}}$ & $4.7 \pm 0.01 \mathbf{a \& b}$ & $3.95 \pm 0.02^{\mathbf{a}} \mathbf{b} \& \mathbf{c}$ \\
\hline Serum albumin (gm/dl) & $4 \pm 0.04$ & $3.2 \pm 0.01 \mathrm{a}$ & $3.8 \pm 0.01 \mathbf{a} \& \mathbf{b}$ & $3.44 \pm 0.02 \mathbf{a , b \& c}$ \\
\hline
\end{tabular}

Data was expressed as Mean \pm SEM. a $p<0.001$ in comparison with the control group. b $p<0.001$ in comparison to the STZ group. c $p<0.001$ in comparison to the Pre-STZ group.
AST: Aspartate aminotransferase.

ALT: Alanine aminotransferase.

ALP: Alkaline phosphatase. 
Table (4): Pearson's correlation coefficient ( $r$ ) between serum levels of asprosin and different studied parameters within STZ group.

\begin{tabular}{lll}
\hline & \multicolumn{2}{l}{ Serum asprosin $(\mathrm{ng} / \mathrm{ml})$} \\
\cline { 2 - 3 } & \multicolumn{1}{c}{$r$} & $p$ \\
\hline Final BMI $\left(\mathrm{gm} / \mathrm{cm}^{2}\right)$ & 0.948 & $<0.01$ \\
Serum glucose $(\mathrm{mg} / \mathrm{dl})$ & -0.979 & $<0.001$ \\
Serum insulin $(\mu \mathrm{IU} / \mathrm{ml})$ & 0.946 & $<0.01$ \\
Serum C-peptide $(\mathrm{ng} / \mathrm{L})$ & 0.85 & $<0.05$ \\
Serum TC $(\mathrm{mg} / \mathrm{dl})$ & -0.966 & $<0.01$ \\
Serum TG $(\mathrm{mg} / \mathrm{dl})$ & -0.969 & $<0.01$ \\
Serum HDL $(\mathrm{mg} / \mathrm{dl})$ & 0.936 & $<0.01$ \\
Serum LDL $(\mathrm{mg} / \mathrm{dl})$ & -0.942 & $<0.01$ \\
Serum VLDL $(\mathrm{mg} / \mathrm{dl})$ & -0.858 & $<0.05$ \\
Atherogenic index & -0.97 & $<0.01$ \\
HbA1c $(\%)$ & -0.918 & $<0.01$ \\
Serum TNFa $(\mathrm{pg} / \mathrm{ml})$ & -0.96 & $<0.01$ \\
Serum AST $(\mathrm{U} / \mathrm{L})$ & -0.977 & $<0.001$ \\
Serum ALT $(\mathrm{U} / \mathrm{L})$ & -0.952 & $<0.01$ \\
Serum ALP $(\mathrm{U} / \mathrm{L})$ & -0.958 & $<0.01$ \\
Serum total bilirubin $(\mathrm{mg} / \mathrm{dl})$ & -0.925 & $<0.01$ \\
Serum direct bilirubin $(\mathrm{mg} / \mathrm{dl})$ & 0.902 & $<0.05$ \\
Serum total $\mathrm{protein}(\mathrm{gm} / \mathrm{dl})$ & 0.867 & $<0.05$ \\
Serum albumin $(\mathrm{gm} / \mathrm{dl})$ & 0.942 & $<0.01$ \\
\hline & & \\
\hline
\end{tabular}

$p<0.05$ indicated statistical significance.

BMI : Body mass index.

TC : Total cholesterol.

TG : Triglycerides.

HDL : High-density lipoprotein.

VLDL : Very low-density lipoprotein.

HbA1c : Glycosylated hemoglobin.

TNFa : Tumor necrosis factor alpha.

AST : Aspartate aminotransferase.

ALT : Alanine aminotransferase.

ALP : Alkaline phosphatase.

\section{Discussion}

The results of this study in STZ group showed a significant increase in serum levels of glucose, TC, TG, LDL, VLDL, TNF x, \% HbA1c and atherogenic index, but, there was a significant decrease in final BMI and serum levels of each of insulin, C-peptide and HDL, in comparison to the control group. This was in agreement with Sireesha, Kasetti [27] and Krause, Riddell [28] who stated that STZ treated rats suffered from weight loss and they referred this to a loss in triglyceride stores and muscle mass. Also, Salahuddin, Jalalpure [29] and Mohamed and Nassier [30] confirmed this weight loss and explained it by the deficiency of insulin that led to decreased amino acids uptake by tissues that resulted in reduction in the level of protein synthesis, and, the increased lipolysis in adipose tissues and protein breakdown. The results of this study were also supported by Rees and Alcolado [21] and Florence, Benoit [31] who confirmed that administration of STZ in rats caused pancreatic swelling and degeneration of $\beta$-cells and induced experimental diabetes mellitus within 2-4 days. Moreover, Koroglu, Senturk [6] and Rath, Panigrahy [5] stated that serum glucose levels were significantly higher in STZ treated group compared to the control group. This was further supported by El-Tantawy and Hassanin [32] and Elabd, Sabry [33] who declared that STZ treatment caused insulin insufficiency and hyperglycemia and they owed this to atrophy and degeneration of $\beta$-cells of the islet of Langerhans. On the other hand, Cnop, Welsh [34] evidenced that STZ treatment was accompanied by $\beta$ cell inflammatory process which occurred as a result of dyslipidemia, hyperglycemia, increased circulating proinflammatory adipocytokines and toxic molecules as reactive oxygen species which played a significant role in islet cell death by inducing DNA damage. Also, in agreement with our results, Jones and Hattersley [35] confirmed that $\mathrm{C}$-peptide was formed in $\beta$-cells of pancreas by cleavage of proinsulin to equal amounts of $\mathrm{C}$ peptide and insulin and they declared that C-peptide can be used to assess the endogenous secretion of insulin. Moreover, Zhang, Wu [36] confirmed that with STZ induced diabetes there was an abnormal lipid profile in the form of elevated triglycerides and LDL but, decreased HDL and they declared that LDL proteins were more vulnerable to oxidation and were considered to be pro-atherogenic. In agreement with our results, Nabi, Kasetti [37] reported decreased atherogenic index in STZ induced diabetes. Also, in line with our results, Pari and Saravanan [38], Sireesha, Kasetti [27] and Rath, Panigrahy [5] found that in untreated diabetes mellitus, $\mathrm{HbA} 1 \mathrm{c}$ was proportionally increased with the increase in fasting blood glucose. Moreover, the results of our study declared that serum asprosin level was significantly reduced in STZ group in comparison to the control. This decrease in serum asprosin may be related to the decrease in body weight and the change in serum glucose and insulin levels in STZ treated rats as supported by Romere, Duerrschmid [1] who confirmed that circulating asprosin concentration was changed with the corresponding change in plasma glucose and insulin and they declared that glucose served as a negative influencer of plasma asprosin levels. They also declared that decreased asprosin level was accompanied by decreased insulin secretion. Furthermore, on assessing liver function changes in STZ group in comparison with the control group, significant increases in serum levels of AST, ALT, ALP and total bilirubin, but, significant decreases in serum direct bilirubin, total protein and albumin levels were found. These results confirmed deteriorated liver functions and this was supported by Ratych and Smith [39] who confirmed presence of high 
levels of AST and ALT, intracellular enzymes used to assess hepatocellular injury, in STZ treated rats. Also, West, Brousil [16] and Leeds, Forman [17] confirmed presence of elevation in serum ALT in patients with type I diabetes mellitus which was associated with poorer glycemic control and raised triglycerides. Moreover, Aragno, Mastrocola [40], Nabi, Kasetti [37], Florence, Benoit [31] and Rath, Panigrahy [5] confirmed the disturbance in liver functions in STZ induced diabetes in the form of significant increases in serum levels of hepatic enzymes and total bilirubin, but, significant decreases in serum direct bilirubin, total protein and albumin levels indicating incidence of hepatocellular damage and they owed this to oxidative stress that occurred secondary to hyperglycemia which decreased antioxidant levels and enhanced free radicals. Also, in this study, correlations in STZ group between serum asprosin level and different studied parameters declared positive associations with final BMI, serum insulin, serum HDL, serum direct bilirubin, total protein and albumin, but, negative associations with serum glucose, TC, TG, LDL,VLDL, TNFa, AST, ALT, ALP, total bilirubin, $\mathrm{HbA1c}$ and atherogenic index. These results declared that asprosin level changes affected glucose homeostasis and hepatic functions and subsequently the pathogenesis and complications of diabetes mellitus which was partially confirmed by [1]. On the other hand, the results of this study in pre-STZ group showed a significant decrease in serum levels of glucose, TC, TG, LDL, VLDL, TNFa, \% HbA1c and atherogenic index, but, there was a significant increase in final BMI and serum levels of each of insulin, C-peptide and HDL, in comparison to the STZ group. These results confirmed that oxytocin prevents marked deterioration in pancreatic $\beta$-cell function with subsequent marked improvement in insulin secretion in comparison to untreated diabetes. This was in line with Clark, Simpson [41], Senturk, Erkanli [42] and Koroglu, Senturk [6] who stated that oxytocin protected $\beta$-cells against oxidative stress produced by STZ treatment by its anti-inflammatory and anti-oxidant effects. This was also supported by Wohaieb and Godin [43] and Yip [12] who declared oxytocin treatment increased weight gain and referred this to the possibility that oxytocin acted in an insulinlike manner. This was further supported by Gavrilenko, Esipov [44], Florian, Jankowski [11] and Suzuki, Honda [13] who demonstrated that oxytocin contributed to the control of blood glucose levels as it promoted glucose uptake in rats, and its involvement in the release of insulin secondary to the presence of its receptors in islets of Langerhans. Also, Klement, Ott $[45]$ found that oxytocin acutely improved $\beta$ cell responsivity and glucose tolerance in healthy men. Moreover, Zhang, Wu [36] found an improvement of glucose tolerance in response to oxytocin in STZ induced diabetes through preventing $\beta$-cell death from streptozotocin toxicity. Furthermore, Suzuki, Honda [13] stated that the impact of oxytocin on insulin secretion may be mediated both centrally via vagal cholinergic neurons innervating $\beta$-cells, as well as peripherally by triggering phosphoinositide and protein kinase $\mathrm{C}$ activation in $\beta$ cells. Our results also confirmed that oxytocin improved $\beta$-cell function as evidenced by increased serum C-peptide in pre-STZ group in comparison to STZ group which was supported by Jones and Hattersley [35] who assessed pancreatic $\beta$-cell function by the measurement of serum C-peptide. On the contrary, Eckertova, Ondrejcakova [46] found that the adipose tissue of rats treated with oxytocin had smaller adipocytes as compared with control and they explained this by activation of proliferator-activated receptor- $y$, a key regulator of adipocyte differentiation. This discrepancy may be due to the difference in the study state as our study assessed effect on diabetic rats. Our results were also in line with El-Tantawy and Hassanin [32] and Mohamed and Nassier [30] who declared that treated diabetic rats had a significant decrease in both blood glucose and HbAlc which was used as a reliable index of diabetic control. Kondeti, Badri [47] explained the decreased HbA1c levels in the treated diabetic rats by the improvement in glycemic control secondary to the increase in insulin secretion from the pancreatic $\beta$-cells in diabetic rats. Moreover, our results were in agreement with Mohamed and Nassier [30] who confirmed the increase in weight of treated diabetic rats and they owed this to the improvement in insulin secretion and action. Also, Nabi, Kasetti [37] reported a decrease in atherogenic index after treatment of diabetes and they referred this effect to the increase in levels of HDL-C which is essential for the transport of cholesterol to the liver from peripheral cells and is a cardioprotective lipid. Moreover, serum asprosin level was significantly increased in pre-STZ group in comparison to the STZ group. This may be occurred secondary to the decrease in blood glucose level and the increase in both body weight, as reflected by the increase in final BMI, and serum insulin level which was supported by Wang, Qu [4] who confirmed that plasma asprosin level was affected by pancreatic $\beta$-cell function. Also, on assessing liver function changes in pre-STZ group in comparison with the STZ group, significant decreases in serum levels of AST, ALT, ALP and total bilirubin, but, significant increases in serum levels of direct bilirubin, total protein and albumin were found. These results 
confirmed that oxytocin had protective effects on liver functions in cases of STZ induced diabetes which was supported by Düşünceli, ișeri [48] and Rahman, Hassan [49] who owed such protective effect to inhibition of both, neutrophil migration and release of proinflammatory cytokines. Also, Rath, Panigrahy [5] found significant decreases in serum levels of hepatic enzymes and total bilirubin, but, significant increases in serum levels of direct bilirubin, total protein and albumin with treatment of STZ induced diabetes, and, they concluded that treatment of diabetes improved hepatic function. Also, the results of this study in post-STZ group showed a significant decrease in serum levels of glucose, TC, TG, LDL, VLDL, TNF x, \% HbA1c and atherogenic index, but, there was a significant increase in serum levels of each of insulin, Cpeptide and HDL, in comparison to the STZ group. Moreover, there was insignificant change in BMI in post-STZ group in comparison to that of STZ group. These results confirmed that exogenous oxytocin treatment deteriorated the changes caused by STZ treatment which was in agreement with Koroglu, Senturk [6] who stated that oxytocin treatment significantly decreased serum glucose levels as compared to the untreated diabetic group. This was also supported by Lee, Uhm [50] and Florian, Jankowski [11] who reported that oxytocin decreased blood glucose level in type I diabetes through its capacity to increase peripheral glucose uptake through an insulin-like signaling pathway. This was further supported by Deblon, VeyratDurebex [51] and Deblon, Veyrat-Durebex [52] who found that oxytocin stimulated glucose oxidation and increased lipolysis and fatty acids $\beta$-oxidation via its direct effect on adipocytes. Also, Elabd, Sabry [33] stated that oxytocin induced no significant change in the body weight of the diabetic treated rats as compared to the diabetic non-treated animals. Moreover, our results were supported by Petersson, Wiberg [53] who confirmed that oxytocin modulated inflammatory processes by stimulating phagocyte migration through affecting levels of growth hormone. Furthermore, Farias, Neto [54] confirmed that HDL protected against oxidative damage of membranes and lipid metabolism by transporting cholesterol from peripheral tissues to the liver through a process known as reverse cholesterol transport. On the other hand, serum asprosin level was significantly increased in post-STZ group in comparison to the STZ group and this may be due to the changes occurred in serum levels of glucose and insulin which confirmed that asprosin had a role in the pathogenesis of STZ induced diabetes and this was supported by Kader, Meltem [3]. Moreover, on assessing liver function changes in post-STZ group in comparison with the STZ group, significant decreases in serum levels of AST, ALT, ALP and total bilirubin, but, significant increases in serum direct bilirubin, total protein and albumin levels were found. These results declared that exogenous oxytocin treatment improved liver function changes that occurred with STZ induced diabetes and this was supported by Düşünceli, işeri [48] who declared that oxytocin treatment improved hepatic functions as evident by decreased serum levels of transaminases. Also, Rath, Panigrahy [5] confirmed that treatment of STZ induced diabetes deteriorated the changes in hepatic functions. In comparison with pre-STZ group, a significant increase in serum levels of glucose, TC, TG, LDL, VLDL, TNF x, \% HbA1c and atherogenic index, but, a significant decrease in serum levels of insulin and HDL was found in post-STZ group. Also, serum asprosin level was significantly decreased in post-STZ group in comparison to the pre-STZ group. these results were supported by Zhang, Chen [55] who found that asprosin levels were negatively related to blood glucose levels. Moreover, on assessing liver function changes in post-STZ group in comparison with the pre-STZ group, significant increases in serum levels of AST, ALT, ALP and total bilirubin, but, significant decreases in serum direct bilirubin, total protein and albumin levels were found. These results confirmed that although exogenous oxytocin treatment after induction of STZ induced diabetes improved the manifestations, yet, it remained less efficient than when oxytocin was given prior to induction of STZ induced diabetes.

\section{Conclusion:}

Asprosin levels were significantly decreased in cases of STZ induced diabetes in comparison with the control, but, increased with oxytocin treatment whether before or after STZ treatment in comparison with STZ group. Also, in STZ group, asprosin was positively correlated with final BMI, serum insulin, serum HDL, serum direct bilirubin, total protein and albumin, but, negatively associated with serum glucose, TC, TG, LDL, VLDL, TNF x, AST, ALT, ALP, total bilirubin, HbA1c and atherogenic index. Thus, changes in circulating asprosin affected glucose homeostasis and subsequently the pathogenesis and complications of diabetes mellitus and might be a predictor of early diagnosis in diabetes mellitus. Also, in STZ group, liver functions were affected in the form of a significant increase in liver enzymes and total bilirubin but, a significant decrease in direct bilirubin, total protein and albumin. Oxytocin treatment pre or post STZ treatment protected or restored the func- 
tional ß-cells, and, improved lipid profile and liver functions. The mechanism through which oxytocin possess antidiabetic activity in STZ induced diabetes could be due to extrapancreatic actions and insulin secretion from the pancreatic $\beta$-cells.

\section{Conflict of Interest:}

Nothing.

\section{References}

1- ROMERE C., et al.: Asprosin, a fasting-induced glucogenic protein hormone. Cell., 165 (3): p. 566-579, 2016.

2- ACARA A.C., et al.: A novel biochemical marker for predicting the severity of acute coronary syndrome with unstable angina pectoris: Asprosin. The American Journal of Emergency Medicine, 2017.

3- KADER U., Y. MELTEM and A. SULEYMAN: Is Asprosin, A Real Actor of Diabetes Etiopathology? Journal of Clinical and Molecular Endocrinology, 3 (2): p. e11 1113,2018

4- WANG Y., et al.: Plasma Asprosin Concentrations Are Increased in Individuals with Glucose Dysregulation and Correlated with Insulin Resistance and First-Phase Insulin Secretion. Mediators of Inflammation, 2018.

5- RATH D., et al.: Antidiabetic effect of extracts of blumea lacera dc. in streptozotocin induced hyperglycemic rats, Vol., 9. 2017.

6- KOROGLU P., et al.: The effect of exogenous oxytocin on streptozotocin (STZ)-induced diabetic adult rat testes. Peptides, 63: p. 47-54, 2015.

7- MEYER-LINDENBERG A., et al.: Oxytocin and vasopressin in the human brain: Social neuropeptides for translational medicine. Nature Reviews Neuroscience, 12 (9): p. 524, 2011

8- KENYON S., et al.: High-dose versus low-dose oxytocin for augmentation of delayed labour. The Cochrane Library, 2013.

9- GIMPL G. and F. FAHRENHOLZ: The oxytocin receptor system: Structure, function, and regulation. Physiological reviews, 81 (2): p. 629-683, 2001.

10- ZIMMET P., K. ALBERTI and J. SHAW: Global and societal implications of the diabetes epidemic. Nature, 414 (6865): p. 782, 2001.

11- FLORIAN M., M. JANKOWSKI and J. GUTKOWSKA: Oxytocin increases glucose uptake in neonatal rat cardiomyocytes. Endocrinology, 151 (2): p. 482-491, 2010.

12- YIP D.: Oxytocin and Its Effect on the Pathological Role of the AGE-RAGE Complex in Cardiovascular Complications of Type I and II Diabetes Mellitus. McGill University Libraries, 2015.

13- SUZUKI M., et al.: The localization of oxytocin receptors in the islets of Langerhans in the rat pancreas. Regulatory Peptides, 183: p. 42-45, 2013.

14- SONG Z., et al.: Supraoptic oxytocin and vasopressin neurons function as glucose and metabolic sensors. American Journal of Physiology-Regulatory, Integrative and Comparative Physiology, 306 (7): p. R447-R456, 2014.
15- HYEON C.K., et al.: Normal serum aminotransferase concentration and risk of mortality from liver diseases: Prospective cohort study. BMJ, 328 (7446): p. 983, 2004.

16- WEST J., et al.: Elevated serum alanine transaminase in patients with type 1 or type 2 diabetes mellitus. Journal of the Association of Physicians, 99 (12): p. 871-876, 2006.

17- LEEDS J., et al.: Abnormal liver function tests in patients with Type 1 diabetes mellitus: Prevalence, clinical correlations and underlying pathologies. Diabetic Medicine, 26 (12): p. 1235-1241, 2009.

18-OLSSON R., et al.: Elevated aminotransferases and alkaline phosphatases in unstable diabetes mellitus without ketoacidosis or hypoglycemia. Journal of Clinical Gastroenterology, 11 (5): p. 541-545, 1989.

19- MUNNS C., et al.: Hepatic glycogenosis: Reversible hepatomegaly in type 1 diabetes. Journal of Paediatrics and Child Health, 36 (5): p. 449-452, 2000.

20- RAGBETLI C. and E. CEYLAN: Effect of streptozotocin on biochemical parameters in rats. Asian Journal of Chemistry, 22 (3): p. 2375, 2010.

21- REES D. and J. ALCOLADO: Animal models of diabetes mellitus. Diabetic Medicine, 22 (4): p. 359-370, 2005.

22- FRÖDE T. and Y. MEDEIROS: Animal models to test drugs with potential antidiabetic activity. Journal of Ethnopharmacology, 115 (2): p. 173-183, 2008.

23- EL A.E.-D.E.-S., et al.: Antifibrotic effect of diethylcarbamazine combined with hesperidin against ethanol induced liver fibrosis in rats. Biomedicine \& Pharmacotherapy, 89: p. 1196-1206, 2017.

24- NOVELLI E., et al.: Anthropometrical parameters and markers of obesity in rats. Laboratory Animals, 41 (1) p. 111-119, 2007.

25- FRIEDEWALD W.T., R.I. LEVY and D.S. FREDRICKSON: Estimation of the concentration of low-density lipoprotein cholesterol in plasma, without use of the preparative ultracentrifuge. Clinical Chemistry, 18 (6): p. 499-502, 1972.

26- KAYAMORI F. and K. IGARASHI: Effects of dietary nasunin on the serum cholesterol level in rats. Bioscience, Biotechnology, and Biochemistry, 58 (3): p. 570-571, 1994.

27- SIREESHA Y., et al.: Antihyperglycemic and hypolipidemic activities of Setaria italica seeds in STZ diabetic rats. Pathophysiology, 18 (2): p. 159-164, 2011.

28- KRAUSE M.P., M.C. RIDDELL and T.J. HAWKE: Effects of type 1 diabetes mellitus on skeletal muscle: Clinical observations and physiological mechanisms. Pediatric Diabetes, 12 (4pt1): p. 345-364, 2011.

29- SALAHUDDIN M., S.S. JALALPURE and N.B. GADGE: Antidiabetic activity of aqueous bark extract of Cassia glauca in streptozotocin-induced diabetic rats. Canadian Journal of Physiology and Pharmacology, 88 (2): p. 153 160, 2010.

30- MOHAMED N.A. and O.A. NASSIER: The antihyperglycaemic effect of the aqueous extract of Origanium vulgare leaves in streptozotocin-induced diabetic rats. Jordan Journal of Biological Sciences, 6 (1): p. 31-38, 2013. 
31- FLORENCE N.T., et al.: Antidiabetic and antioxidant effects of Annona muricata (Annonaceae), aqueous extract on streptozotocin-induced diabetic rats. Journal of Ethnopharmacology, 151 (2): p. 784-790, 2014.

32- EL-TANTAWY, W. and L. HASSANIN: Hypoglycemic and hypolipidemic effects of alcoholic extract of Tribulus alatus in streptozotocin-induced diabetic rats: A comparative study with T. terrestris (Caltrop), 2007.

33- ELABD S., et al.: Oxytocin as a novel therapeutic option for type I diabetes and diabetic osteopathy. Endocrine Regulations, 48 (2): p. 87-102, 2014.

34- CNOP M., et al.: Mechanisms of pancreatic ß-cell death in type 1 and type 2 diabetes: Many differences, few similarities. Diabetes, 54 (Suppl 2): p. S97-S107, 2005.

35- JONES A. and A. HATTERSLEY: The clinical utility of C-peptide measurement in the care of patients with diabetes. Diabetic Medicine, 30 (7): p. 803-817, 2013.

36- ZHANG H., et al.: Treatment of obesity and diabetes using oxytocin or analogs in patients and mouse models PloS one, 2013. 8(5): p. e6 1477.

37- NABI S.A., et al.: Antidiabetic and antihyperlipidemic activity of Piper longum root aqueous extract in STZ induced diabetic rats. BMC Complementary and Alternative Medicine, 13 (1): p. 37, 2013.

38- PARI L. and G. SARAVANAN: Antidiabetic effect of Cogent $\mathrm{db}$, a herbal drug in alloxan-induced diabetes mellitus. Comparative Biochemistry and Physiology Part C: Toxicology \& Pharmacology, 131 (1): p. 19-25, 2002.

39- RATYCH R.E. and G.W. SMITH: Anatomy and physiology of the liver. Shackleford's surgery of the alimentary tract. 3 rd ed. Philadelphia: WB Saunders, 1991: p. 273-86, 2002 .

40- ARAGNO M., et al.: Oxidative stress impairs skeletal muscle repair in diabetic rats. Diabetes, 53 (4): p. $1082-$ 1088, 2004.

41- CLARK S.L., et al.: Oxytocin: New perspectives on an old drug. American Journal of Obstetrics \& Gynecology, 200 (1): p. 35. e1-35. e6, 2009.

42- SENTURK G.E., et al.: The protective effect of oxytocin on ischemia/reperfusion injury in rat urinary bladder. Peptides, 40: p. 82-88, 2013.

43- WOHAIEB S.A. and D.V. GODIN: Alterations in free radical tissue-defense mechanisms in streptozocin-induced diabetes in rat: Effects of insulin treatment. Diabetes, 36 (9): p. 1014-1018, 1987.

44- GAVRILENKO V., V. ESIPOV and K. SIVOZHELEZOV: Morphological characteristic of wound healing process in patients with diabetic purulent-necrotic foot lesion treated with oxytocin. Morfologiia (Saint Petersburg, Russia), 124 (5): p. 24-27, 2003.

45- KLEMENT J., et al.: Oxytocin improves $\beta$-cell responsivity and glucose tolerance in healthy men. Diabetes, 66 (2): p. $264-271,2017$.

46- ECKERTOVA M., et al.: Subchronic treatment of rats with oxytocin results in improved adipocyte differentiation and increased gene expression of factors involved in adipogenesis. British Journal of Pharmacology, 162 (2): p. $452-463,2011$.

47- KONDETI V.K., et al.: Effect of Pterocarpus santalinus bark, on blood glucose, serum lipids, plasma insulin and hepatic carbohydrate metabolic enzymes in streptozotocininduced diabetic rats. Food and Chemical Toxicology, 48 (5): p. 1281-1287, 2010

48- DÜŞÜNCELI F., et al.: Oxytocin alleviates hepatic ischemia-reperfusion injury in rats. Peptides, 29 (7): p. 1216-1222, 2008.

49- RAHMAN Z.A., W.A. HASSAN, and A. EL-GARHY: The possible protective effects of oxytocin on cisplatininduced toxicity in female rats. Acta Scientiae et Intellectus, 2 (2), 2016.

50- LEE E.S., et al.: Oxytocin stimulates glucose uptake in skeletal muscle cells through the calcium-CaMKK-AMPK pathway. Regulatory Peptides, 151 (1-3): p. 71-74, 2008.

51- DEBLON N., et al.: Mechanisms of the Anti-Obesity Effects of Oxytocin in Diet-Induced Obese., 2011.

52- DEBLON N., et al.: Mechanisms of the anti-obesity effects of oxytocin in diet-induced obese rats. PloS one, 6 (9): p. e25565, 2011.

53- PETERSSON M., et al.: Oxytocin decreases carrageenan induced inflammation in rats. Peptides, 22 (9): p. 1479 1484,2001

54- FARIAS R., ET AL., Effects of Croton cajucara extract on serum lipids of rats fed a high fat diet. Phytotherapy Research, 10 (8): p. 697-699, 1996.

55- ZHANG L., et al.: Circulating asprosin concentrations are increased in type 2 diabetes mellitus and independently associated with fasting glucose and triglyceride. Clinica Chimica Acta., 2017. 


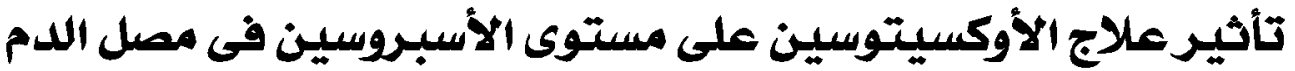

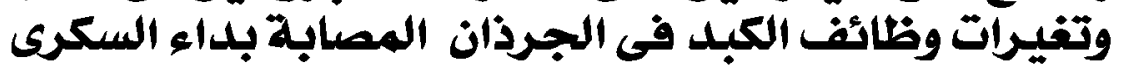 المستحث بالستريتوزوتوسين الجرذين بانيان}

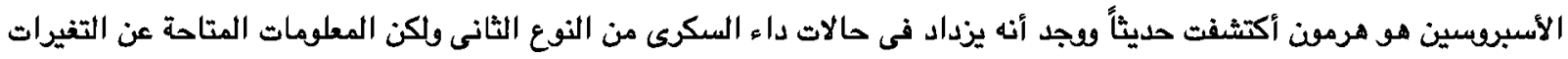

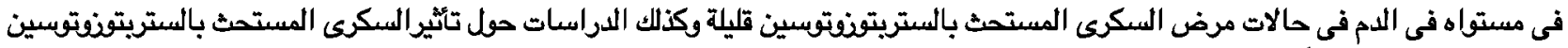

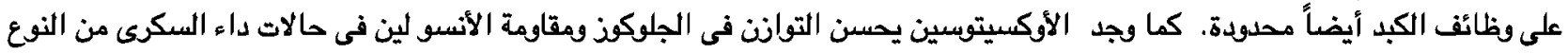

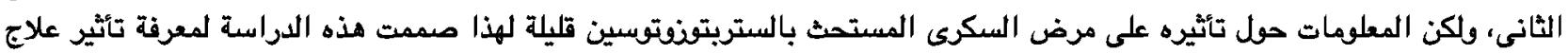

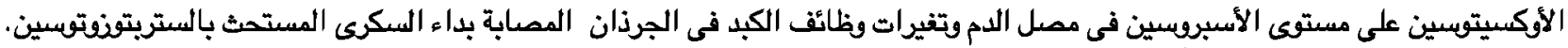
ولتحقيق ذلك تم أستخدام ع جرذاً قسمت على أريع مجموعات متساوية كما يلى: المجموعة الأولى: الضعابطة.

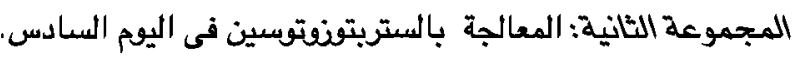

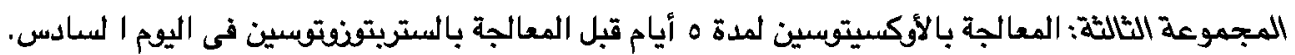

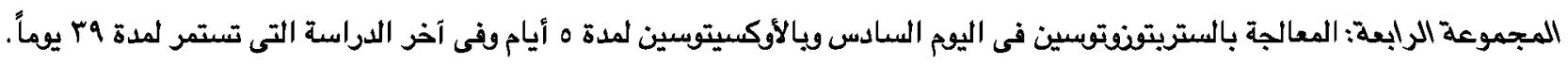

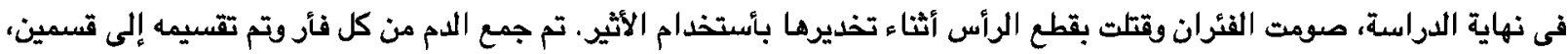

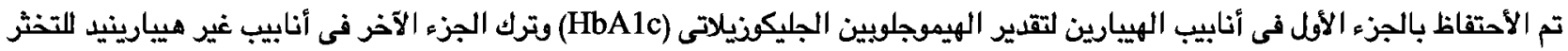

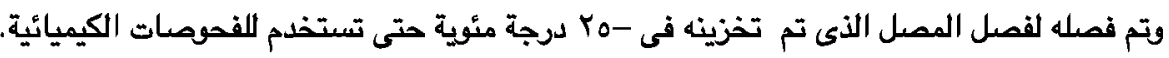
ولقد أسفرت الدراسة عن النتائج الأثية:

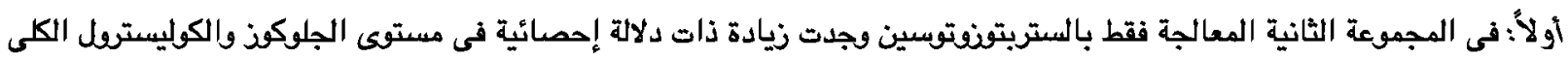

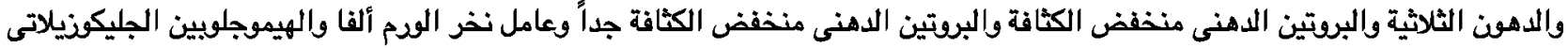

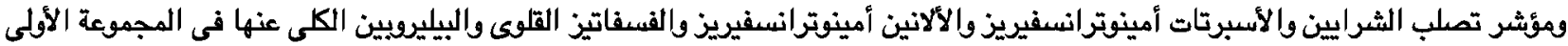

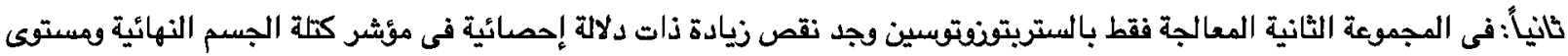

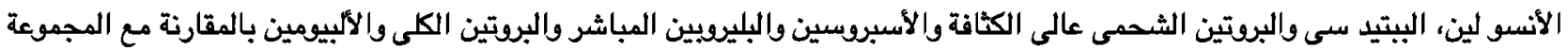
الأولى الضابطة.

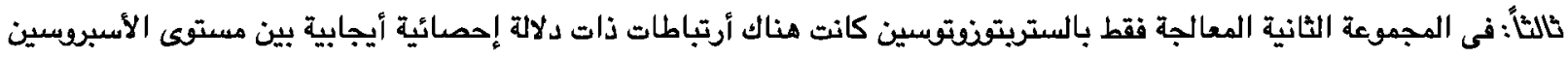

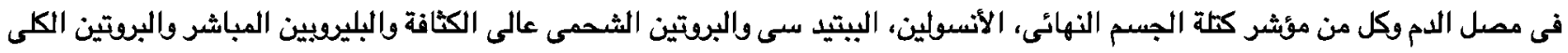
فى الدم والألبومين.

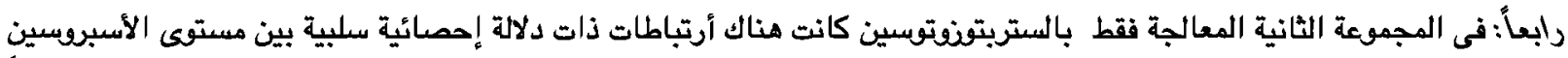

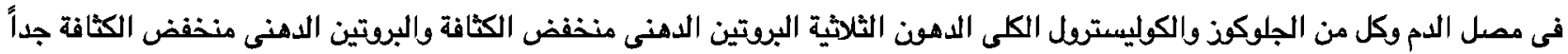

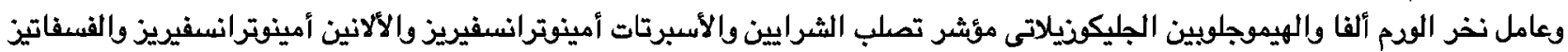

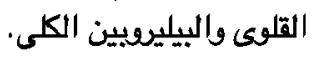

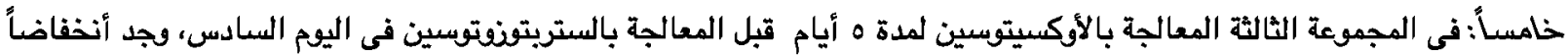

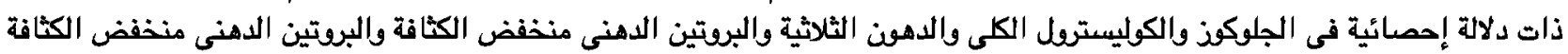

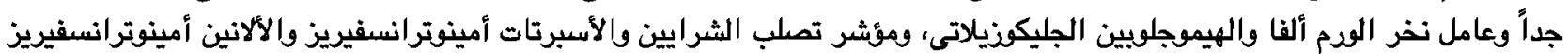
والفسفاتيز القلوى والبيليروبين الكلى.

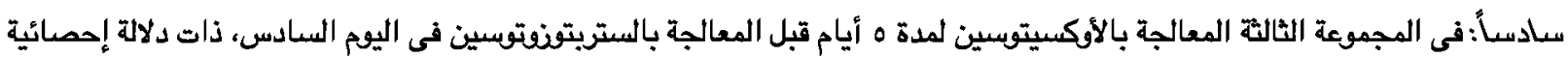

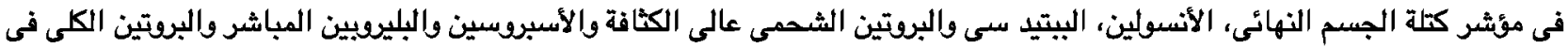

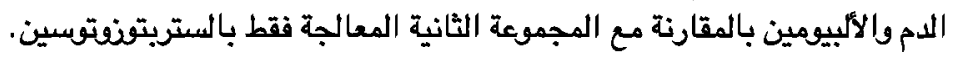


سابعاً: فى المجموعة الرابعة المعالجة فقط بالستريتونوتوسين فى اليوم السادس وبالأوكسيتوبسين لمدة ه أيام فى آخر الدراسة وجد

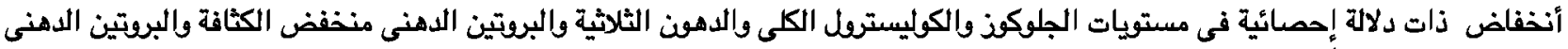
منخفض الكثافة جداً وعامل نخر الودم ألفا والهيموجلوبين الجليكنيلاتى، ومؤشر تصلب الشرايين والأسبرتات أمينوترانسفيريز والألانين

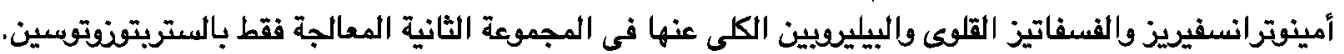

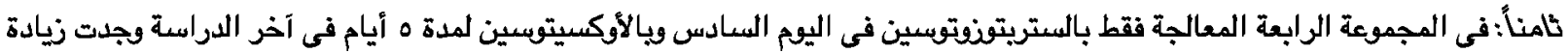

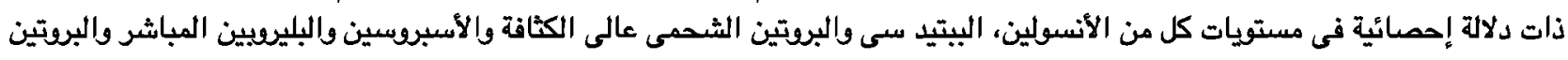

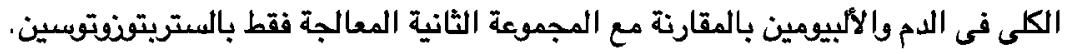

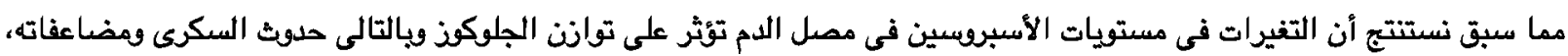

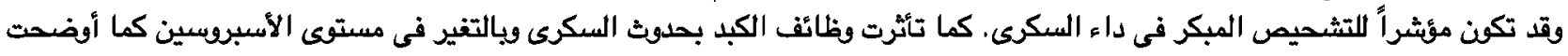

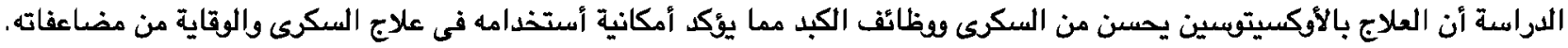

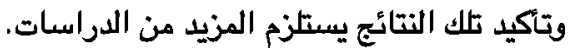

